\title{
Facet Syndrome: A Hidden Culprit in Neck and Low Back Pain?
}

\section{Deepak Anap ${ }^{1 *}$, Subhash Khatri² and Sushil Kachewar ${ }^{3}$}

${ }^{1}$ Associate Professor, College of Physiotherapy, PIMS, Loni, Maharashtra, India ${ }^{2}$ Professor \& Principal, College of Physiotherapy, PIMS, Loni, Maharashtra, India ${ }^{3}$ Associate Professor, Department of Radiodiagnosis, PIMS, Loni, Maharashtra, India

Lumbar spinal facet joints were first suggested in the medical literature as a source of low back and lower extremity pain in 1911[1]. Since then, the so-called "facetogenic back pain" has become a widely accepted, although still controversial entity in the radiologic and orthopaedic literature [2-6]. Estimates of the prevalence of lumbar facet joint pain based on single diagnostic blocks have been reported to range from $7.7 \%$ to $75 \%$ among patients reporting back pain [7].

Schwarzer et al. [8] determined that facet joint involvement was the root cause of lower back pain in the United States following an incident (work related, motor vehicle accident, or other causes) in about $15 \%$ of the patients. The prevalence of lumbar facet joint pain in a rheumatology practice in Australia was noted to be $40 \%$ [9].

In 1927, Putti illustrated osteoarthritic changes of facet joint in 75 cadavers of persons older than 40 years [10]. In 1933, Ghormley coined the term facet syndrome, suggesting that hypertrophic changes secondary to osteoarthritis of the zygapophysial processes led to the lumbar nerve root entrapment, which caused LBP [11]. In the 1950s, Harris and Mcnab [12] determined that the etiology of facet joint degeneration was secondary to intervertebral disc degeneration.

The facet or zygapophysial joints of the spine are well innervated by the medial branches of the dorsal rami $[13,14]$. Facet joints have been shown to be capable of causing pain in the neck, upper and mid back, and lower back. This pain may be referred to the head or upper extremity, chest wall, and lower extremity as has been found in normal volunteers [15]. In accordance with postulates of Bogduk the lumbar facet joints are innervated, they produce pain in normal volunteers, and relief of pain has been demonstrated by using diagnostic techniques of known reliability and validity. Conversely, the reliability of physical examination in diagnosing the specific cause of back pain has been questioned [16].

Despite all studies, the diagnosis of facet joint-mediated pain remains a challenge because no particular history or clinical examination manoeuvre has been found to be unique or specific to this entity [17]. Schwarzer et al. and other authors have reported up to a $45 \%$ false-positive diagnostic rate when the physical examination findings are correlated to diagnostic medial branch blocks of the posterior rami [18].

Biomechanical studies of the facet joint during extension and of facet capsular ligaments strained during rotation initially provided the belief that facet joint pain is worse with extension and rotation. Early studies by Helbig and Lee provided initial credence to this belief, but later studies by Revel and co authors and by Schwarzer and colleagues did not support it. Revel's investigation found that an increase in pain during hyperextension and extension-rotation was, in fact, less frequent in the group that responded to the facet joint injection than in the group that did not [19]. Further, it has been shown that medical imaging provides only a little additional information in identifying the precise anatomical diagnosis.

The mechanism of chronic neck pain and low back pain, specifically secondary to facet joints, continues to be controversial. Kirkaldy-Willis et al. [20] described the pathogenesis of degenerative changes in the aging spine, whereas Handel et al. described a structural degenerative cascade for the cervical spine. In this model, degenerative cascade is viewed in a context of three-joint complex, with involvement of changes in the disc structure and composition paralleling changes in the articular cartilage and ligaments of joints. Thus, it is reasonable to assume that in a patient suffering with neck and low back pain, the causative structures of that pain may be the same in both regions, either discs or facet joints. The potential for correlation of pain generators in cervical and lumbar spine is exemplified by demonstration of similar degeneration of disc in cervical and lumbar spine in twins [21].

Many investigators developed techniques to diagnose facet joint pain using intra-articular joint blocks and medial branch nerve blocks, as well as ways to treat such pain with intra-articular steroids, surgical ablation, or Radiofrequency (RF) denervation. Although controversy still continues regarding the true prevalence, most accurate diagnostic methods, and most efficacious treatment of symptomatic facet syndrome as the cause of back pain [22] ; the future appears to be bright with rapid advances in the filed of imaging for diagnosis and in the filed of physiotherapy for long term and effective management of such conditions. Hence through this editorial we appeal one and all to look at Facet Syndrome as a hidden culprit in back pain and to device means and methods to diagnose and manage this enigma.

\section{References}

1. Goldthwait JE (1911) The lumbosacral articulation. An explanation of many cases of lumbago, sciatica, and paraplegia. Boston Med and Surg J 164: 365372 .

2. Lewinnek GE, Warfield CA (1986) Facet joint degeneration as a cause of low back pain. Clin Orthop Relat Res : 216-222.

3. Helbig T, Lee CK (1988) The lumbar facet syndrome. Spine (Phila Pa 1976) 13: $61-64$.

4. Carrera GF, Haughton VM, Syvertsen A, Williams AL (1980) Computed tomography of the lumbar facet joints. Radiology 134: 145-148.

5. Raskin SP (1981) Degenerative changes of the lumbar spine: assessment by computed tomography. Orthopedics 4: 186-195.

6. Badgley CE (1941) The articular facets in relation to low-back pain and sciatic radiation. J Bone Joint Surg 23: 481-496.

7. Dreyer SJ, Dreyfuss PH (1996) Low back pain and the zygapophysial (facet) joints. Arch Phys Med Rehabil 77: 290-300.

8. Schwarzer AC, Aprill CN, Derby R, Fortin J, Kine G, et al. (1994) Clinica features of patients with pain stemming from the lumbar zygapophysial joints. Is the lumbar facet syndrome a clinical entity? Spine (Phila Pa 1976) 19: 1132 1137.

9. Schwarzer AC, Wang SC, Bogduk N, McNaught PJ, Laurent R (1995) Prevalence and clinical features of lumbar zygapophysial joint pain: a study in an Australian population with chronic low back pain. Ann Rheum Dis 54 100-106.

*Corresponding author: Deepak Anap, Associate Professor, College of Physiotherapy, PIMS, Loni, Maharashtra, India, E-mail: deepak.anap@hotmail.com

Received July 30, 2012; Accepted August 21, 2012; Published August 23, 2012

Citation: Anap D, Khatri S, Kachewar S (2012) Facet Syndrome: A Hidden Culprit in Neck and Low Back Pain? J Spine 1:e105. doi:10.4172/2165-7939.1000e105

Copyright: ( 2012 Anap D, et al. This is an open-access article distributed under the terms of the Creative Commons Attribution License, which permits unrestricted use, distribution, and reproduction in any medium, provided the original author and source are credited. 
10. Putti $\bigvee(1927)$ New conceptions in the pathogenesis of sciatic pain. Lancet 2: 53-60.

11. Ghormley RK (1933) Low back pain with special reference to the articular facets, with presentation of an operative procedure. JAMA 101: 1773-1777.

12. Harris Rli, Macnab I (1954) Structural changes in the lumbar intervertebral discs; their relationship to low back pain and sciatica. J Bone Joint Surg $\mathrm{Br}$ 36-36B: 304-22.

13. Bogduk N (1982) The clinical anatomy of the cervical dorsal rami. Spine (Phila Pa 1976) 7: 319-330.

14. Chua WH, Bogduk N (1995) The surgical anatomy of thoracic facet denervation. Acta Neurochir (Wien) 136: 140-144.

15. Fukui S, Ohseto K, Shiotani M, Ohno K, Karasawa H, et al. (1996) Referred pain distribution of the cervical zygapophyseal joints and cervical dorsal rami. Pain 68: 79-83.

16. Bogduk N, McGuirk B (2002). In Medical Management of Acute and Chronic Low Back pain. An Evidence-Based Approach: Pain Research and Clinical Management. Elsevier Science BV. 13:127-138.
17. Kayser R, Mahlfeld K, Heyde CE (2008) [Concepts of in-patient gradual diagnostics for patients with lumbar back-pain]. Orthopade 37: 285-299.

18. Schwarzer AC, Aprill CN, Derby R, Fortin J, Kine G, et al. (1994) The relative contributions of the disc and zygapophyseal joint in chronic low back pain Spine (Phila Pa 1976) 19: 801-806

19. Revel ME, Listrat VM, Chevalier XJ, Dougados M, N'guyen MP, et al. (1992) Facet joint block for low back pain: identifying predictors of a good response. Arch Phys Med Rehabil 73: 824-828.

20. Kirkaldy-Willis WH, Wedge JH, Yong-Hing K, Reilly J (1978) Pathology and pathogenesis of lumbar spondylosis and stenosis. Spine (Phila Pa 1976) 3 319-328.

21. Sambrook PN, MacGregor AJ, Spector TD (1999) Genetic influences on cervical and lumbar disc degeneration: a magnetic resonance imaging study in twins. Arthritis Rheum 42: 366-372.

22. Bokov A, Isrelov A, Skorodumov A, Aleynik A, Simonov A, et al. (2011) An analysis of reasons for failed back surgery syndrome and partial results after different types of surgical lumbar nerve root decompression. Pain Physician 14: $545-557$ 